\title{
Possession of a Controlled Substantive: Light 'have' and Other Verbs of Possession
}

\author{
John Beavers, Elias Ponvert, and Stephen Wechsler \\ University of Texas at Austin
}

\section{Introduction}

Verbs like get, give, and transitive want incorporate a possession component, and hence receive paraphrases that include the verb have as given in (1):

(1) a. John wants the car. $\leftrightarrow$ John wants to have the car.

b. John got the car. $\leftrightarrow$ John came to have the car.

c. Mary gave John the car. $\leftrightarrow$ Mary caused John to have the car.

Evidence for an underlying "have" comes from durative adverbials, which may modify the "have" state (McCawley 1974, Ross 1976, Dowty 1979, inter alia):
a. John wants the car (for two days).
(want or have for two days)
b. John got the car (for two days).
(have for two days)
c. John gave me the car (for two days).
(have for two days)

Furthermore, with want both events can be modified at the same time as in (3a), something not possible with non-possession verbs as in (3b).

a. On Monday, John wanted a car Tuesday. (want Monday, have Tuesday)

b. \#On Monday, John painted a car Tuesday.

This suggests these sentences have an underlying semantic 'have' formative. Two theories have been proposed for how this formative enters the picture. On one view it is in the lexical decomposition of the verb, as in (4a) for give (Dowty 1979, Rappaport Hovav and Levin 2008). The other posits a silent syntactic formative (McCawley 1974), as in the analysis of Harley (2003: 34, (3b)) in (4b), where $\mathrm{P}_{\text {have }}$ raises and adjoins to $v_{\text {cause }}$, which Spells-Out as give (Harley 2003: 34, (3b)).

a. give $:=[\mathrm{x}$ CAUSE $[\mathrm{z}$ HAVE $\mathrm{y}]]$

b.

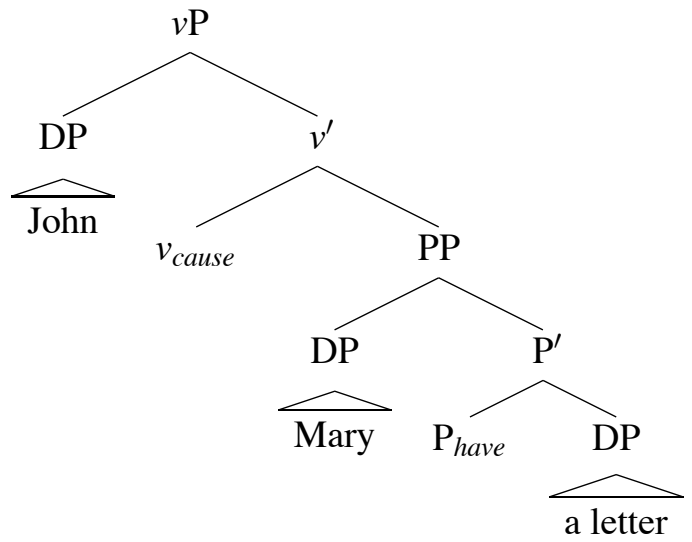


Similarly, have is be $+\mathrm{P}_{\text {have }}$ and get is $v_{\text {become }}+\mathrm{P}_{\text {have }}$. The syntactic analysis in particular seems to capture the ambiguity with durative adverbials naturally: it corresponds simply to an attachment ambiguity.

However, drawing upon a broader investigation of polysemy, pragmatics, and other considerations, we argue against both of these approaches, and propose instead a third (albeit still lexicalist) analysis. We propose that the possessum nominal (the car in the above examples) is augmented in all cases with an additional possessor argument by the same process independently needed for adding the possessor argument to the noun car in John's car (Barker 1995, Vikner and Jensen 2002). The verbs in each case are uniformly raising/control verbs, extending the analysis of Partee (1999) for have with relational nouns like sister.

In $\S 2$, we show that patterns of polysemy and pragmatic function are parallel across the verbs have, get, give, want, and the genitive construction, suggesting a unified analysis of the semantics of possession beyond the specific verbs, arguing against a strictly lexical decompositional analysis as in (4a). We also show that facts from idiom formation and syntax are problematic for the syntactic analysis in (4b), leaving our proposed analysis as an alternative. The intuition behind our proposal is sketched in $\S 3$. A syntactic sketch (formalized in HPSG) is given in $\S 4$, and a semantic analysis is presented using Minimal Recursion Semantics (MRS) (Copestake et al. 2005) that captures the modifier ambiguity without positing a syntactic formative. We give additional motivation for this analysis in $\S 5$, as well as reasons for preferring it over lexical decompositions. We conclude in $\S 6$.

\section{The Functions of 'have' and its Relatives}

Expressing a possession relation is but one of the functions of the verb have. First, for a relational noun like sister, have acts as a light verb marking an argument of the semantic relation denoted by its complement DP as in (5a). This use is subject to the definiteness effect, wherein the complement may not be a definite DP (cp. \#John has thelevery sister; Partee 1999: 1, (1)). For non-relational nouns like car or window in (5b-d), Tham (2006) noticed an interesting contrast between definites and indefinites. Indefinites allow an alienable possession reading as in (5b), and Tham assimilates this to Partee's (indefinite) relational nouns via a default alienable possession relation that arises when the noun fails to supply one. But Tham notes that definites require one of two other readings. One possibility is what Tham calls a "control" reading as in (5c), which indicates that the subject of have has control over the object without necessarily possessing it, which requires a true cognitive agent as possessor (cp. Where are the mirrors? John/\#The bathroom has them). Alternatively, have can pick up its relation from a rich discourse context as in (5d). To take one of Tham's examples, suppose cleaning duties are being divvied up and someone asks what John will be cleaning. The reply in (5d) means in effect 'John will be cleaning the windows.' 

a. John has a sister.
b. John has a car.
c. John has the car (for the weekend).
d. John has the windows (to clean).

(inalienable possession)

(alienable possession)

(control possession)

(focus possession)

Control and focus readings are also possible with indefinites (e.g. John has a car for the weekend/to clean). Thus have appears to be multiple ways ambiguous, disambiguated by properties of its noun complement.

Interestingly, want and get have exactly the same range of functions:
a. John wants/got a sister.
(inalienable possession)
b. John wants/got a car.
(alienable possession)
c. John wants/got your car (for the weekend).
(control possession)
d. John wants/got the windows (to clean).
(focus possession)

Give also allows all four readings, although here it is the indirect object and not the subject that is the possessor/controller:
a. John gave Bill a black eye.
b. John gave Bill a car.
c. John gave Bill the car (for the weekend).
d. John gave Bill the windows (to clean).

(inalienable possession)

(alienable possession)

(control possession)

(focus possession)

This shared systematic polysemy is explained if we assume that these sentences all share a polysemous semantic formative - the same formative that durative adverbials take scope over in (2). The question is whether this formative is introduced through the decomposition of each verb, the syntactic context, or somewhere else.

An argument that this formative is syntactic is put forth by McCawley (1974), and more recently revived by Richards (2001) and Harley (2004). They note that there exist parallel verb+DP idioms across have, want, get, and give, such as give/get the creeps and give/take/get flak:

a. John gave everyone flak.

b. You get flak (when you take a stand)

They explain the parallelism by positing a single underlying idiom, "HAVE flak", which then combines with causal or inchoative semantic formatives:

a. John CAUSE everyone [ HAVE flak ].

b. You BECOME [ HAVE flak ].

However, following Wechsler (2008) we believe the facts point in the opposite direction. In particular, the collocations exhibiting parallelism (get flak, give flak, etc.) are not really idioms, but rather compositional phrases involving figurative senses of the DP plus the standard meaning of the verbs. For example, flak refers to 'a barrage of abuse or adverse criticism', and frequently appears in corpora without any of these verbs (cp. I expect flak, Why all the flak?, etc.) Meanwhile, true 
non-compositional idioms do not exhibit parallelism. For example, have a baby on the 'give birth to a baby' meaning does not transfer to the other verbs (pace Harley 2004), as shown in (10) (from Wechsler 2008).

(10) a. Natalie doesn't want to have a baby, so she's going to adopt one.

b. \#Natalie doesn't want a baby, so she's going to adopt one.

As shown by the contrast in (10), the phrase want a baby, in contrast to have a baby, is general with respect to the ways of satisfying this desire, and not ambiguous between 'want to give birth to a baby' and other possibilities such as adoption.

Furthermore, there is considerable syntactic evidence against a silent syntactic HAVE formative. Wechsler (2008) provides evidence from passivization, adjective formation, Exceptional Case Marking, coordination of complements, infinitival relatives, adverb intervention, modification by right, particle shift, coordination of verbs, diachrony, and comparison with cognate languages. Space limitations preclude us from reproducing all of this evidence here, but it is all based upon the demonstration that the word string such as a car has exactly the same syntactic structure in want a car as it does in any other context such as see a car. Hence it is just a DP here and lacks the PP shell shown in (4b), or indeed any other shell. To take one example, infinitival relatives allow pied piping of PPs (a bench on which to sit) but disallow DP relativization (*a bench which to sit on). If the complement of want were a PP as claimed then it should be possible to relativize it in infinitivals, but it is not: *a reasonable type of bike $\left[P_{\text {have }} \text { which }\right]_{P P}$ to want for commuting.

\section{Our Proposal: DP is the Locus of Possessional Semantics}

We argue for a lexical analysis here, but suggest an alternative to the decomposition of verbs (à la Dowty 1979: 269-270). First, exactly the same range of interpretations seen in (5)-(7) is also found with English 's genitive possessors as shown in (11).
a. John's sister
b. John's car
c. John's hotel room (for the weekend)
d. John's windows (for cleaning)

(inalienable possession)

(alienable possession)

(control possession)

(focus possession)

Therefore the observed polysemy pattern is not restricted to these verbs, suggesting a more general analysis across all types of possession constructions, rather than a strictly lexical decomposition analysis. We propose to analyze the locus of the possessional semantics as coming largely from the possessed DP, where have, want, give, and get are raising/control verbs. We weave together two previous strands of thought on this topic: Barker (1995) and Vikner and Jensen (2002) on genitive possessors, and Partee (1999) on have as a light verb with relational nouns.

It is usually assumed that inherently relational nouns like sister have one more argument than non-relational nouns like car, where the denotation of sister is a function mapping siblings to sets of their sisters, while the denotation of car 
is the set of cars (Partee 1999: 3, Barker 1995: 51). Thus in standard extensional $\lambda$-theoretic terms the two nouns differ as follows:

$$
\begin{aligned}
& \text { a. } \llbracket \operatorname{car} \rrbracket:=\lambda x\left[\operatorname{car}^{\prime}(x)\right] \\
& \text { b. } \llbracket \operatorname{sister} \rrbracket:=\lambda y \lambda x\left[\operatorname{sister}^{\prime}(x, y)\right]
\end{aligned}
$$

In John's sister, John is the sibling argument of sister, so that the denotation of John's sister is the set of all $x$ such that $\operatorname{sister}^{\prime}\left(\mathbf{j o h n}^{\prime}, x\right)$ (Barker 1995: 52). To account for the genitive argument in John's car, Barker (1995: 54) proposes the special null determiner in (13a) that type-raises a non-relational noun to a relational noun as in (13b), where the possessional relationship between the possessor and the possessed is represented by his $\pi$ operator:

$$
\begin{array}{ll}
\text { a. } & \llbracket \emptyset_{[P O S S} \rrbracket=\lambda P \lambda y \lambda x[\pi(y, x) \wedge P(x)] \\
\text { b. } \llbracket \emptyset_{[P O S S]} \rrbracket(\llbracket \operatorname{car} \rrbracket)=\lambda y \lambda x\left[\pi(y, x) \wedge \operatorname{car}^{\prime}(x)\right]
\end{array}
$$

Thus a uniform treatment can be given for genitives with both relational nouns and non-relational nouns, the difference being in how the appropriate denotation is derived: for relational nouns the possessor argument is lexicalized, while for nonrelational nouns it is derived. More recently Vikner and Jensen (2002) have proposed that the possessive pumping rule is actually a family of rules, each positing a different argument that stands in a different relation to the head noun. Following Pustejovsky (1995), they propose that each rule pulls out a different aspect of the Qualia Structure of the head noun. For example, they have a pumping rule that turns an agent from the Telic Qualia of a verb like book into an argument of book, producing John's book on the sense that John wrote the book (though we ignore agentive, i.e. non-stative, genitives here). This limits the possibilities for the extra argument to those determined by the lexical semantics of the head noun, though they also have one pumping rule that adds an argument that stands in an unspecified, pragmatically controlled relation. We follow Barker in assuming an unspecified $\pi$-type relation that may be interpreted in a constrained set of ways, though we generally agree with Vikner and Jensen that the possible relations are partly lexically determined.

Turning to have, Partee (1999) accounts for the relationship of the possessors in his sister and he has a sister by positing that have is a light verb that raises an argument of an inherently relation noun to subject position. She assumes that a quantifier like $a$ has a denotation like (14a) to deal with explicitly relational nouns. When (14a) is applied to (12b), it generates the meaning in (14b), i.e. a generalized quantifier also looking for an $<e>$-type argument. Partee then proposes the denotation in (14c) for light have that promotes the unsaturated relational argument of the relational generalized quantifier to its own unsaturated argument. Furthermore, to deal with the as yet unsaturated scope of the generalized quantifier, she proposes that have provides a trivial function exists ${ }^{\prime}$ (true of any argument, e.g. $\lambda z[z=z]$ ). This produces the denotation of (14d) for have a sister, which is of type $\langle e, t\rangle$ and thus is the type of a regular VP. ${ }^{1}$

\footnotetext{
${ }^{1}$ The exists ${ }^{\prime}$ function here is borrowed from Barwise and Cooper (1981), and is supposed to explain the definiteness effect with relational nouns in a similar manner to their explanation of the definiteness effect in existentials, though we set this issue aside here.
} 


$$
\begin{array}{ll}
\text { a. } & \llbracket \mathrm{a} \rrbracket:=\lambda R \lambda x \lambda P[\exists y[Q(x, y) \wedge P(x)]] \\
\text { b. } & \llbracket \text { a sister } \rrbracket=\lambda x \lambda P \exists y\left[\operatorname{sister}^{\prime}(x, y) \wedge P(y)\right] \\
\text { c. } & \text { [have } \rrbracket=\lambda R \lambda w\left[R(w)\left(\text { exist }^{\prime}\right)\right] \\
\text { d. } & \text { [have a sister } \rrbracket=\llbracket \text { have } \rrbracket(\llbracket a \text { sister } \rrbracket)=\lambda w \exists y\left[\operatorname{sister}^{\prime}(w, y) \wedge \operatorname{exists}^{\prime}(y)\right]
\end{array}
$$

We combine and extend these analyses. While Partee only posited light have for relational nouns, we posit light have for all non-auxiliary uses of the verb. For relational nouns this is identical to Partee's analysis, though we offer an account that allows us to eliminate the exists $s^{\prime}$ predicate. For non-relational nouns, we assume a type-raising rule similar to Barker's that turns non-relational nouns into relational nouns. We furthermore propose that other verbs of possession are likewise raising verbs, differing primarily in the degree of extra semantics (intensional operators, causation, inchoativization) they ascribe to the event in question. We implement this analysis in a Head-driven Phrase Structure Grammar, using Minimal Recursion Semantics to capture the sublexical scope mentioned in $\S 2$. See Egg (1999) for a similar analysis of the sublexical scope of German wieder 'again'.

\section{HPSG Formalization}

\subsection{Possessed DPs}

We assume that all lexemes have a predicate argument structure (ARG-ST), which is constrained by the Argument Realization Principle to be the sum of three separate syntactic valence lists on its CAT(EGORY) feature: specifiers (SPR), complements (COMPS), and subjects (SUBJ) (Ginzburg and Sag 2000: 23). This is codified in (15) as a constraint on all elements of type lexeme: ${ }^{2}$

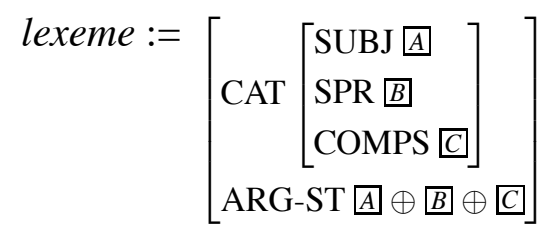

Noun lexemes in English have additional categorial constraints on their valents. Subjects of nouns are DPs, while specifiers must be genitive DPs, and there may be at most one of each. These are shown in (16) for type noun-lxm (which is a subtype of (15) and thus inherits its constraints). ${ }^{3}$

\footnotetext{
${ }^{2}$ The feature path leading to the CAT feature in Ginzburg and Sag (2000) is S(YN)S(EM) | LOC(AL), where all local syntactic/semantic information is located; we omit this for readability. The semantic feature CONT(ENT) is also here.

${ }^{3}$ In addition, the valence feature COMPS is constrained to be a list of non-DPs (including PPs and clauses). However, since we do not treat of-PPs (a sister of John) or post-nominal genitives ( $a$ sister of John's) in this paper, we ignore COMPS here.
} 


$$
\text { noun-lxm }:=\text { lexeme \& }\left[\operatorname{CAT}\left[\begin{array}{l}
\operatorname{SUBJ}\langle(\mathrm{DP})\rangle \\
\operatorname{SPR}\langle(\operatorname{DP}[\mathrm{CASE} \text { gen }])\rangle
\end{array}\right]\right]
$$

The constraints in (16) ensure that any DP argument on the ARG-ST of a noun can be realized in one of two different ways. For example, all relational nouns take a possessor DP on their ARG-ST, as in (17) (ignoring semantics for now; we assume all arguments of nouns are semantically obligatory, but may be existentially bound off to permit syntactic optionality).

$$
\text { rel-noun-lxm (Preliminary) }:=\text { noun-lxm \& }[\mathrm{ARG}-\mathrm{ST}\langle\ldots \mathrm{DP} \ldots\rangle]
$$

The constraints in (16) ensure that this DP must appear on some valence list. If it is a SPR then it must be a genitive DP, producing phrases like John's sister. If it is a SUBJ, then a raising verb is required to realize it (which we return to below).

Turning to non-relational nouns like car, we posit a lexicalist analogue of Barker's null determiner, namely the Possessor Addition Lexical Rule in (18). This rule maps a noun-lxm to a noun-lxm with an additional DP shuffled onto its ARGST, where $\bigcirc$ represents the shuffle operation (principles for lexical rules in HPSG ensure that all other syntactic constraints associated with a particular noun-lxm are preserved in the output). This is similar to the Predicative NP Lexical Rule of Pollard and Sag (1994: 360n), which converts a normal DP such as a doctor into a predicative one as in John is a doctor by adding a DP argument directly into its SUBJ, predicating the property denoted by the input of the added argument, and marking the output as a syntactic predicate by the feature [ PRED + ] shared with predicative AdjPs, VPs, and PPs (where the default for all non-predicative nouns is [ PRED - ]). Our rule differs in that (a) the added DP argument is shuffled onto ARG-ST and thus can appear in SPR or SUBJ and (b) the output is not marked $[$ PRED + ] (we discuss the semantics below).

$$
\begin{aligned}
& \text { Possessor Addition Lexical Rule (Preliminary): } \\
& {\left[\begin{array}{l}
\text { noun-lxm } \\
\text { ARG-ST } ₫
\end{array}\right] \Longrightarrow[\text { ARG-ST } ₫ \bigcirc\langle\text { DP }\rangle]}
\end{aligned}
$$

This rule therefore yields all the same argument realization possibilities as lexical relational nouns. Before we analyze raising, we outline Minimal Recursion Semantics (MRS) (Copestake et al. 2005), since it will be crucial in capturing many of the above properties. Readers familiar with MRS are invited to skip the next subsection.

\subsection{Minimal Recursion Semantics}

MRS is a framework for building meaning representations with very little recursive structure, in particular regarding quantifier scope. In MRS, scope (qua representational embedding) is left unspecified and is resolved post-compositionally, subject 
to independent constraints on well-formed formulae in some meaning representation language (e.g. first order predicate calculus with no free variables or vacuous quantification). Thus one MRS representation can sometimes resolve to multiple well-formed formulae. MRS is therefore not a theory of semantics, but rather a model of meaning representations that can be mapped onto a theory of semantics.

The basic unit in MRS is an Elementary Predication (EP), which consists of a predicate name and a list of arguments of that predicate. There is no $\lambda$-abstraction; instead variables are bound through scope resolution. Every (non-pleonastic) lexeme has a KEY EP that represents its core semantics. For example, the KEY for $\operatorname{dog}$ is $\operatorname{dog}^{\prime}(x)$, where $x$ is an open variable over individuals. Every EP also has a label representing its relative scope in the ultimate meaning representation; these are notated by a colon (e.g. $h 0: \operatorname{dog}^{\prime}(x)$ represents an EP with a handle $h 0$ ). Any EPs with the same label have the same scope and are interpreted conjunctively, so that the two EPs in the set $\left\{h 0: \operatorname{dog}^{\prime}(x), h 0: \operatorname{large} e^{\prime}(x)\right\}$ correspond to the single scopal unit $\left[\operatorname{dog}^{\prime}(x) \wedge \operatorname{large}^{\prime}(x)\right]$ in first-order logic. Scopal EPs take handle arguments, which are eventually resolved to specific labels of other EPs. The KEY for a scopal modifier like probably is probably $(h 1)$, where $h 1$ represents a handle to be equated with some label, so that for the two EPs in the set $\left\{h 0: \operatorname{probably}^{\prime}(h 1), h 2: \operatorname{die}^{\prime}(x)\right\}$, if $h 1=h 2$ then this set corresponds to $\operatorname{probably}^{\prime}\left(\operatorname{die}^{\prime}(x)\right)$ in first-order logic. The KEY EP for a quantifier like every is every ${ }^{\prime}(x, h 3, h 4)$, where $x$ is the bound variable, $h 3$ is the handle of the quantifier's restriction and $h 4$ the handle of its scope.

Constraints on possible scope are built up compositionally in terms of a relation Equality Modulo Quantifiers $\left(=_{q}\right)$, where for handle argument $h 1$ and label $h 2$, if $h 1={ }_{q} h 2$ then either $h 1=h 2$ or there is some $h 3$ such that $h 1={ }_{q} h 3, h 3={ }_{q}$ $h 2$, where crucially $h 3$ is the scope handle of a quantifier. In other words, $=q$ constraints allow quantifiers, but nothing else, to scope between a scopal EP and its argument EP(s). For probably die above, if $h 1={ }_{q} h 2$ there are two readings for someone probably died. If someone intervenes between probably and die ( $h 1={ }_{q}$ $h 3, h 3={ }_{q} h 2$ for scope handle $h 3$ of someone $)$, we get $\operatorname{probably}^{\prime}\left(\exists x\left[\operatorname{person}^{\prime}(x) \wedge\right.\right.$ die $\left.\left.^{\prime}(x)\right]\right)$. Otherwise, $h 1=h 2$ and the quantifier must outscope both, producing $\exists x\left[\operatorname{person}^{\prime}(x) \wedge \operatorname{probably}^{\prime}\left(\operatorname{die}^{\prime}(x)\right)\right]$.

An MRS meaning representation (also called an MRS) for a syntactic constituent (lexical or phrasal) is a tuple $\langle G T, L T, R E L S, H C O N S\rangle$. GT is the global top label shared by all constituents in a clause (which we ignore), and $L T$ is the local top label upon which scopal constraints are stated during composition. REL(ATION)S is a bag of EPs (an unordered set that allows repeats). For lexemes it consists only of the lexeme's KEY EP, but for phrases it is the union of the RELS lists of all of the constituent's daughters. HCONS is a set of $={ }_{q}$ constraints, which is empty for lexemes but for phrases is the union of the HCONS lists of all of the daughters.

Scopal constraints are introduced syntactically, depending on the head of a constituent. If a constituent is headed by a scopal element, the constituent has the $G T$ and $L T$ of its scopal daughter, and some handle argument of its head's KEY is constrained to be $={ }_{q}$ the $L T$ of its non-scopal daughter (assuming binary branching). For quantifiers this is always the restriction scopal argument. Therefore, given an MRS like (19a) for every and an MRS like (19b) for dog, every dog is as in (19c) 
(borrowing the example from Copestake et al. 2005: 301). ${ }^{4}$
a. every: $\left\langle h 0, h 1,\left\{h 2: \operatorname{every}^{\prime}(x, h 3, h 4)\right\},\{\}\right\rangle$
b. $\operatorname{dog}:\left\langle h 0, h 5,\left\{h 5: \operatorname{dog}^{\prime}(y)\right\},\{\}\right\rangle$
c. every dog: $\left\langle h 0, h 1,\left\{h 2: \operatorname{every}^{\prime}(x, h 3, h 4), h 5: \operatorname{dog}^{\prime}(x)\right\},\left\{h 3={ }_{q} h 5\right\}\right\rangle$

This is essentially a generalized quantifier for variable $x$ whose restriction is $\operatorname{dog}^{\prime}(x)$ (there being no possible intervening quantifiers), but the scope $(h 4)$ is unspecified.

For a non-scopal heads the $G T$ and $L T$ of the mother and both daughters are equated. Thus if loves has the MRS in (20a) and takes (19c) as its complement, it produces the MRS in (20b) (the equation of $x$ in (19c) and $z$ in (20a) happens through syntactic coindexation).
a. loves: $\left\langle h 0, h 6,\left\{h 6:\right.\right.$ loves $\left.\left.^{\prime}(y, z)\right\},\{\}\right\rangle$
b. loves every dog: $\left\langle h 0, h 6,\left\{h 6:\right.\right.$ loves $^{\prime}(y, z), h 2:$ every $^{\prime}(z, h 3, h 4)$, $\left.\left.h 5: \operatorname{dog}^{\prime}(z)\right\},\left\{h 3={ }_{q} h 5\right\}\right\rangle$

This is a predicate looking for its subject, and the scope of the quantifier is still left unconstrained. Combining this with some girl as in (21a) produces (21b).
a. some girl: $\left\langle h 0, h 7,\left\{h 8: \operatorname{some}(x, h 9, h 10), h 11: \operatorname{girl} l^{\prime}(x)\right\},\left\{h 9={ }_{q} h 11\right\}\right\rangle$
b. some girl loves every dog: $\left\langle h 0, h 6,\left\{h 8: \operatorname{some}^{\prime}(y, h 9, h 10), h 11: \operatorname{girl}^{\prime}(y)\right.\right.$, $\left.\left.h 6: \operatorname{loves}^{\prime}(y, z), h 2: \operatorname{every}^{\prime}(z, h 3, h 4), h 5: \operatorname{dog}^{\prime}(z)\right\},\left\{h 3={ }_{q} h 5, h 9={ }_{q} h 11\right\}\right\rangle$

The phrase is syntactically complete, but while the restriction on each quantifier is constrained to be $={ }_{q}$ the label of its DP complement, in both cases the scope is left undetermined. Thus this MRS is not fully scope resolved. However, rules for wellformed first order logic formulae with no free variables or vacuous quantification only permit two resolutions: (a) $h 10={ }_{q} h 2$ (some scopes over every) and $h 4={ }_{q} h 6$ (every scopes over loves) or (b) $h 4={ }_{q} h 8$ (every scopes over some) and $h 10={ }_{q} h 6$ (some scopes over loves). This gives us two formulae in the standard representation for scope-resolved MRSs, which produce the standard ambiguity of this sentence:

$$
\begin{array}{ll}
\text { a. } & \operatorname{some}^{\prime}\left(y, \operatorname{girl}^{\prime}(y), \operatorname{every}^{\prime}\left(z, \operatorname{dog}^{\prime}(z), \operatorname{loves}^{\prime}(y, z)\right)\right) \\
& \left(\approx \exists y\left[\operatorname{girl}^{\prime}(y) \wedge \forall z\left[\operatorname{dog}^{\prime}(z) \rightarrow \operatorname{loves}^{\prime}(y, z)\right]\right]\right) \\
\text { b. } & \text { every }^{\prime}\left(z, \operatorname{dog}^{\prime}(z), \operatorname{some}^{\prime}\left(y, \operatorname{girl}^{\prime}(y), \operatorname{loves}^{\prime}(y, z)\right)\right) \\
& \left(\approx \forall z\left[\operatorname{dog}^{\prime}(z) \rightarrow \exists y\left[\operatorname{girl}^{\prime}(y) \wedge \operatorname{loves}^{\prime}(y, z)\right]\right]\right)
\end{array}
$$

The crucial points to remember are that (a) non-quantifiers have their relative scope set by syntax, providing a rigid order for these elements in the final meaning representation and (b) quantifiers are allowed to scope freely over and between these elements and thus may have variable scope, which is determined post-syntactically by rules that convert an MRS into well-formed formulae.

\footnotetext{
${ }^{4}$ For quantifiers the $L T$ is distinct from the label of the KEY EP, but for other elements they are identical. This allows more flexibility in where quantifiers may be interpreted.
} 


\subsection{Possessed DPs from an MRS Perspective}

We assume a poss ${ }^{\prime}$ EP that takes a possessor $x$ and possessum $y$, i.e. $\operatorname{poss}^{\prime}(x, y)$, which can be interpreted in several different ways, giving us the systematic polysemy of possession constructions. We augment the definition of relational nouns and possessor addition as follows (where $y$ is the index of the relational noun) ${ }^{5}$

$$
\begin{aligned}
& \text { rel-noun-lxm (Revised) := noun-lxm \& } \\
& {\left[\text { ARG-ST }\left\langle\ldots \operatorname{DP}_{x}[\operatorname{CONT}\langle h 0, h 1,\{h 1: \text { poss }(x, y), \ldots\},\{\}\rangle] \ldots\right\rangle\right]} \\
& \text { Possessor Addition Lexical Rule (Revised): } \\
& {\left[\begin{array}{l}
\text { noun-lxm } \\
\text { ARG-ST } ₫
\end{array}\right] \Longrightarrow} \\
& {\left[\begin{array}{l}
\text { ARG-ST } \left.₫ \bigcirc\left\langle\operatorname{DP}_{x}\left[\operatorname{CONT}\left\langle h 0, h 1,\left\{h 1: \operatorname{poss}^{\prime}(x, y), \ldots\right\},\{\}\right\rangle\right]\right\rangle\right]
\end{array}\right.}
\end{aligned}
$$

Thus all relational nouns (lexical or derived) take a DP argument that introduces a poss $^{\prime}$ EP constraining the DP to be the possessor of the relational noun. If sister is a relational noun introducing a sister ${ }^{\prime} \mathrm{EP}$ on its RELS list, and its possessor argument is on SPR realized by John's, we would have the following representation for John's sister (where $y$ is the index of sister and we assume proper names have no RELS and contribute constant indices, given in boldface; we ignore the definite reading):

$$
\text { John's sister: }\left[\operatorname{CONT}\left\langle h 0, h 1,\left\{h 1: \operatorname{sister}^{\prime}(y), h 1: \operatorname{poss}^{\prime}(\mathbf{j o h n}, y)\right\},\{\}\right\rangle\right]
$$

However, if the possessor is the SUBJ, then it cannot be realized within the DP. Instead it requires a raising verb, to which we turn next.

\subsection{Raising Verbs and Adverbial Scope}

Raising-to-subject verbs (e.g. appear, seem, be) take a complement with an unsaturated subject and identify that subject with their own,as in (26).

$$
\text { subj-raising-v-lxm :=v-lxm \& }[\text { ARG-ST }\langle\square D P,[\text { CAT } \mid \operatorname{SUBJ}\langle\square\rangle]\rangle]
$$

All 'standard' raising verbs are of a subtype (26) that selects only [ PRED + ] complements. For possession, we posit a separate subtype of raising-to-subject verbs given in (27) that specifically selects for a [ PRED - ] DP complement with a possessor subject. ${ }^{6}$

\footnotetext{
${ }^{5}$ Copestake et al. (2005) also give a feature structural representation for MRS for greater compatibility with HPSG. However, this produces very large Attribute-Value Matrices. Thus for purposes of space we continue to use the tuple notation to represent the CONT(ENT) value of a feature structure.

${ }^{6}$ Since DPs are by default [ PRED - ], the only [ PRED + ] DPs are those generated by Pollard and Sag's Predicate NP Lexical Rule. Since this rule introduces predicational rather than possessional semantics, a reading for I am a doctor identical to I have a doctor is ruled out.
} 


$$
\begin{aligned}
& \text { poss-subj-raising-v-lxm := subj-raising- } v \text {-lxm \& } \\
& {\left[\operatorname{ARG-ST}_{\operatorname{DP}}, \mathrm{DP}_{y}\left[\mathrm{CAT}\left[\begin{array}{l}
\mathrm{HEAD} \mid \mathrm{PRED}- \\
\left.\operatorname{SUBJ}\left\langle\left[\operatorname{CONT}\left\langle h 0, h 1,\left\{h 1: \operatorname{poss}^{\prime}(x, y), \ldots\right\},\{\}\right\rangle\right]\right\rangle\right]
\end{array}\right]\right\rangle\right]}
\end{aligned}
$$

Have, want, and get are all of type (27), where the difference between them is in their idiosyncratic semantics. For example, have is pleonastic but equates its $L T$ with the label of its subject (which is also the label of poss' by (26)):

$$
\text { have, }\left[\begin{array}{l}
\text { poss-subj-raising-v-lxm } \\
\operatorname{CONT}\langle h 0, h 7,\{\},\{\}\rangle \\
\text { ARG-ST }\langle[\operatorname{CONT}\langle h 0, h 7, \ldots\rangle], \ldots\rangle
\end{array}\right]
$$

To generate have a sister, we first assume $a$ has an MRS similar to that of every in (19a), so that $a$ sister with an unrealized SUBJ has the CONT and CAT in (29b).

$$
\text { a sister: }\left[\begin{array}{l}
\left.\operatorname{CAT} \mid \operatorname{SUBJ}\left\langle\operatorname{DP}\left[\operatorname{CONT}\left\langle h 0, h 6,\left\{h 6: \operatorname{poss}^{\prime}(x, y), \ldots\right\},\{\}\right\rangle\right]\right\rangle\right] \\
\left.\operatorname{CONT}\left\langle h 0, h 5,\left\{h 2: a^{\prime}(x, h 3, h 4), h 1: \operatorname{sister}^{\prime}(y)\right\},\left\{h 3={ }_{q} h 1\right\}\right\rangle\right]
\end{array}\right.
$$

Thus the resolved denotation of $a$ sister is that of a generalized quantifier, but there is still an argument bearing a possession relation that must be saturated (cp. Partee's representation in (14b)). When have is combined with a sister we get (30).

(30) have a sister :

$$
\left[\begin{array}{l}
\operatorname{CAT} \mid \operatorname{SUBJ}\left\langle\operatorname{DP}\left[\operatorname{CONT}\left\langle h 0, h 7,\left\{h 7: \operatorname{poss}^{\prime}(x, y), \ldots\right\},\{\}\right\rangle\right]\right\rangle \\
\operatorname{CONT}\left\langle h 0, h 7,\left\{h 2: a^{\prime}(x, h 3, h 4), h 1: \operatorname{sister}^{\prime}(y)\right\},\left\{h 3={ }_{q} h 1\right\}\right\rangle
\end{array}\right]
$$

In other words, have a sister has the same semantics and valence as a sister, save that the $L T$ of have a sister is the same as that of the possessor relation of its subject, meaning effectively that poss' has the scope of the main verb of the sentence.

Combining this with John (ignoring tense agreement) produces the MRS in (31). Since John is coidentified with the subject of sister it bears the poss ${ }^{\prime}$ EP, which is thus introduced onto the RELS of the entire constituent.

\section{John has a sister :}

$$
\left\langle h 0, h 7,\left\{h 7: \operatorname{poss}^{\prime}\left(\mathbf{j o h n}^{\prime}, y\right), h 2: a^{\prime}(x, h 3, h 4), h 1: \operatorname{sister}^{\prime}(y)\right\},\left\{h 3={ }_{q} h 1\right\}\right\rangle
$$

Although $a^{\prime}$ has its restriction (sister $(y)$ ), its scope is unresolved. The only possible scope to produce a well-formed formula is the possession relation $\left(h 4={ }_{q} h 7\right)$, producing the following scope-resolved structure:

$$
a^{\prime}\left(y, \operatorname{sister}^{\prime}(y), \operatorname{poss}^{\prime}\left(\mathbf{j o h n}^{\prime}, y\right)\right)\left(\approx \exists y\left[\operatorname{sister}^{\prime}(y) \wedge \operatorname{poss}^{\prime}\left(\mathbf{j o h n}^{\prime}, y\right)\right]\right)
$$

Non-pleonastic raising verbs introduce a scopal KEY lexically specified to scope over poss'. This is an intensional EP for want and an inchoative EP for get $\left(\mathrm{DP}_{\text {foo }}\right.$ abbreviates a DP with a foo $\mathrm{EP}$ on its RELS): 
a. want,

$$
\left[\begin{array}{l}
\text { poss-subj-raising-v-lxm } \\
\left.\operatorname{CONT}\left\langle h 0, h 7,\left\{h 7: \text { want }^{\prime}(x, h 8)\right\},\left\{h 8=_{q} h 6\right\}\right\rangle\right\rangle \\
\operatorname{ARG-ST}\left\langle\mathrm{XP}_{x}, \operatorname{DP}_{y}\left[\operatorname{SUBJ}\left\langle\operatorname{DP}_{h 6: p o s s^{\prime}(x, y)}\right\rangle\right]\right\rangle
\end{array}\right]
$$

b. get, [poss-subj-raising-v-lxm

$$
\left[\begin{array}{l}
\text { poss-subj-raising-v-lxm } \\
\left.\operatorname{CONT}\left\langle h 0, h 7,\left\{h 7: \text { become }^{\prime}(h 8)\right\},\left\{h 8={ }_{q} h 6\right\}\right\rangle\right\rangle \\
\operatorname{ARG-ST}\left\langle\operatorname{XP}_{x}, \operatorname{DP}_{y}\left[\operatorname{SUBJ}\left\langle\operatorname{DP}_{h 6: p o s s^{\prime}(x, y)}\right\rangle\right]\right\rangle
\end{array}\right]
$$

Give differs from the rest in that it is raising-to-object predicate (the details of this type should be obvious from above) and introduces causal semantics:

$$
\text { give, }\left[\begin{array}{l}
\text { poss-obj-raising-v-lxm } \\
\operatorname{CONT}\left\langle h 0, h 7,\left\{h 7: \text { cause }^{\prime}(z, h 8)\right\},\left\{h 8={ }_{q} h 6\right\}\right\rangle \\
\operatorname{ARG-ST}\left\langle\operatorname{DP}_{z}, \operatorname{DP}_{x}, \operatorname{DP}_{y}\left[\operatorname{SUBJ}\left\langle\operatorname{DP}_{h 6: \text { poss }^{\prime}(x, y)}\right\rangle\right]\right\rangle
\end{array}\right]
$$

The MRS for John wants a car is given in (35) (again ignoring tense).

John wants a car:

$\left\langle h 0, h 7,\left\{h 7:\right.\right.$ want $^{\prime}\left(\mathbf{j o h n}^{\prime}, h 8\right), h 6: \operatorname{poss}^{\prime}\left(\mathbf{j o h n}^{\prime}, x\right), h 2: a^{\prime}(x, h 3, h 4)$, $\left.\left.h 1: \operatorname{car}^{\prime}(x)\right\},\left\{h 3={ }_{q} h 1, h 8={ }_{q} h 6\right\}\right\rangle$

This MRS is similar to (31) save that it includes a want ${ }^{\prime}$ EP in addition to the poss $\mathrm{EP}$, where the $h 8={ }_{q} h 6$ constraint ensures that want ${ }^{\prime}$ scopes over poss ${ }^{\prime}$ modulo quantifiers. Thus $a^{\prime}$ may scope over either EP, correctly predicting two readings: ${ }^{7}$

a. $\operatorname{want}^{\prime}\left(\mathbf{j o h n}^{\prime}, a^{\prime}\left(x, \operatorname{car}^{\prime}(x), \operatorname{poss}^{\prime}\left(\mathbf{j o h n}^{\prime}, x\right)\right)\right)$

"John wants there to be a car he has"

b. $a^{\prime}\left(x, \operatorname{car}(x)\right.$, want $\left.^{\prime}\left(\mathbf{j o h n}^{\prime}, \operatorname{poss}^{\prime}\left(\mathbf{j o h n}^{\prime}, x\right)\right)\right)$

"There is a car such that John wants to have it."

Crucially, this also gives us a lexical account of the temporal adverb scope facts of want. Assuming on Tuesday in John wants a car on Tuesday is a definite generalized quantifier over time (interval) variables (following Pratt and Francez 2001: 197), there are three possible scope positions for each reading in (36): over want $^{\prime}$, $a^{\prime}$, or poss $^{\prime}$, producing six readings for the MRS in (37) (augmenting our EPs with time variables, and assuming that quantifiers share this variable with their scope): ${ }^{8}$

\footnotetext{
${ }^{7}$ Dowty (1979: 246) notes that an analysis like (36a) does not predict the existence of the car, due to the intensional operator, predicting the possibility of John wants a unicorn.

${ }^{8}$ We use $t \subseteq t^{\prime}$ as shorthand for an EP representing an inclusion relation where $t^{\prime}$ includes $t$. As is common with event variables, we assume any unbounded time variables are wide-scope existentially bound by default (cp. Copestake et al. 2005: 312).
} 
John wants a car on Tuesday:

$\left\langle h 0, h 7,\left\{h 7:\right.\right.$ want $^{\prime}\left(t, \mathbf{j o h n}^{\prime}, h 8\right), h 6: \operatorname{poss}^{\prime}\left(t^{\prime}, \mathbf{j o h n} \mathbf{n}^{\prime}, y\right), h 2: a^{\prime}\left(t^{\prime \prime}, x, h 3, h 4\right)$, $\left.h 1: \operatorname{car}^{\prime}(y), h 9: \operatorname{the}^{\prime}\left(t^{\prime \prime \prime}, h 10, h 11\right), h 12: t^{\prime \prime \prime \prime} \subseteq \operatorname{tuesday}^{\prime}\right\},\left\{h 3={ }_{q} h 1, h 8={ }_{q}\right.$ $\left.h 6, h 10={ }_{q} h 12\right\}$ )

a. $t h e^{\prime}\left(t, t \subseteq\right.$ tuesday $^{\prime}$, want $\left.^{\prime}\left(t, \mathbf{j o h n}^{\prime}, a^{\prime}\left(t^{\prime}, x, \operatorname{car}^{\prime}(x), \operatorname{poss}^{\prime}\left(t^{\prime}, \mathbf{j o h n}^{\prime}, x\right)\right)\right)\right)$

b. $\operatorname{want}^{\prime}\left(t, \mathbf{j o h n}^{\prime}, \operatorname{the}^{\prime}\left(t^{\prime}, t^{\prime} \subseteq\right.\right.$ tuesday $\left.\left.^{\prime}, a^{\prime}\left(t^{\prime}, x, \operatorname{car}^{\prime}(x), \operatorname{poss}^{\prime}\left(t^{\prime}, \mathbf{j o h n} \mathbf{n}^{\prime}, x\right)\right)\right)\right)$

c. $\operatorname{want}^{\prime}\left(t, \mathbf{j o h n} \mathbf{n}^{\prime}, a^{\prime}\left(t^{\prime}, x, \operatorname{car}^{\prime}(x), \operatorname{th}^{\prime}\left(t^{\prime}, t^{\prime} \subseteq\right.\right.\right.$ tuesday $\left.\left.\left.^{\prime}, \operatorname{poss}^{\prime}\left(t^{\prime}, \mathbf{j o h n} \mathbf{n}^{\prime}, x\right)\right)\right)\right)$

d. $\operatorname{the}^{\prime}\left(t, t \subseteq\right.$ tuesday $\left.^{\prime}, a^{\prime}\left(t, x, \operatorname{car}^{\prime}(x), \operatorname{want}^{\prime}\left(t, \mathbf{j o h n}^{\prime}, \operatorname{poss}^{\prime}\left(t^{\prime}, \mathbf{j o h n} \mathbf{n}^{\prime}, x\right)\right)\right)\right)$

e. $a^{\prime}\left(t, x, \operatorname{car}^{\prime}(x), t h e^{\prime}\left(t, t \subseteq\right.\right.$ tuesday $\left.\left.^{\prime}, \operatorname{want}^{\prime}\left(t, \mathbf{j o h n}^{\prime}, \operatorname{poss}^{\prime}\left(t^{\prime}, \mathbf{j o h n} \mathbf{n}^{\prime}, x\right)\right)\right)\right)$

f. $a^{\prime}\left(t, x, \operatorname{car}^{\prime}(x), \operatorname{want}^{\prime}\left(t, \mathbf{j o h n}^{\prime}, t h e^{\prime}\left(t^{\prime}, t^{\prime} \subseteq\right.\right.\right.$ tuesday $\left.\left.\left.^{\prime}, \operatorname{poss}^{\prime}\left(t^{\prime}, \mathbf{j o h n}^{\prime}, x\right)\right)\right)\right)$

This produces the desired effect: on Tuesday outscopes either the poss' or want relation, something that follows from the way MRS handles quantifier scope. A similar ambiguity holds for get, where John got a car on Tuesday can either mean John assumed possession on Tuesday (but the possession may have lasted beyond Tuesday), or the period of possession was on Tuesday. Similarly for give. However, with strictly durative adverbs like for an hour, only want allows an ambiguity:

a. John wanted a car for an hour.

(want or have for an hour).

b. John got a car for an hour.

(have for an hour).

c. Bill gave John a car for an hour.

(have for an hour).

Ambiguity is blocked for get and give because those two verbs, unlike want, are achievements, and thus are ineligible to be scoped over by a strictly durative adverb.

Finally, pre-sentential temporal modifiers may only scope over the verb, but not the underlying possession relation, giving only one reading to On Monday, John wanted a car. ${ }^{9}$ This is a common property of pre-sentential modifiers, including locative and restitutive modifiers (see Dowty 1979: 250ff.):
a. In Prague, John wanted a car.
(want in Prague, not have in Prague)
b. Again, John wanted a car.
(want again, not have again)

Although we have no new insights on pre-sentential modifiers, we can easily accommodate them through a variant of the analysis Dowty (1979: 264-269) proposed for scope ambiguities with accomplishments (e.g. John opened the door again), in which every adverb is ambiguous between a VP or S modifier (or there are different rules for adverbs in different positions). The scope of $\mathrm{S}$ modifiers is simply fixed to be $={ }_{q}$ the $L T$ of the $\mathrm{S}$ it modifies. This produces the following MRS for $O n$ Tuesday, John wants a car, which is identical to (37) except that the scope $h 11$ of On Tuesday is fixed to be $=_{q}$ the $L T h 7$ of want, yielding just three readings: ${ }^{10}$

\footnotetext{
${ }^{9}$ It is possible for a pre-sentential modifier to scope over poss' if it is a fronted VP-modifier (Dowty 1979: 265), usually requiring special topicalization intonation (e.g. TODAY, John wants a car? Why not get it TOMORROW?). This is predicted if we assume an additional fronting rule.

${ }^{10}$ Technically, on Dowty's analysis VP-modifiers also have high scope, and the low scope reading is generated by meaning postulate. On our analysis no meaning postulate is necessary.
} 
On Tuesday, John wants a car :

$\left\langle h 0, h 7,\left\{h 7:\right.\right.$ want $^{\prime}\left(t, \mathbf{j o h n}^{\prime}, h 8\right), h 6: \operatorname{poss}^{\prime}\left(t^{\prime}, \mathbf{j o h n}{ }^{\prime}, y\right), h 2: a^{\prime}\left(t^{\prime \prime}, x, h 3, h 4\right)$, $\left.h 1: \operatorname{car}^{\prime}(y), h 9: \operatorname{the}^{\prime}\left(t^{\prime \prime \prime}, h 10, h 11\right), h 12: t^{\prime \prime \prime \prime} \subseteq \operatorname{tuesday}^{\prime}\right\},\left\{h 3={ }_{q} h 1, h 8={ }_{q}\right.$ $\left.\left.h 6, h 10={ }_{q} h 12, h 11={ }_{q} h 7\right\}\right\rangle$

a. $t h e^{\prime}\left(t, t \subseteq\right.$ tuesday $^{\prime}$, want $\left.^{\prime}\left(t, \mathbf{j o h n}^{\prime}, a^{\prime}\left(t^{\prime}, x, \operatorname{car}^{\prime}(x), \operatorname{poss}^{\prime}\left(t^{\prime}, \mathbf{j o h n}^{\prime}, x\right)\right)\right)\right)$

b. $\operatorname{the}^{\prime}\left(t, t \subseteq\right.$ tuesday $\left.^{\prime}, a^{\prime}\left(t, x, \operatorname{car}^{\prime}(x), \operatorname{want}^{\prime}\left(t, \mathbf{j o h n}^{\prime}, \operatorname{poss}^{\prime}\left(t^{\prime}, \mathbf{j o h} \mathbf{n}^{\prime}, x\right)\right)\right)\right)$

c. $a^{\prime}\left(t, x, \operatorname{car}^{\prime}(x), \operatorname{the}^{\prime}\left(t, t \subseteq\right.\right.$ tuesday $\left.\left.^{\prime}, \operatorname{want}^{\prime}\left(t, \mathbf{j o h n}^{\prime}, \operatorname{poss}^{\prime}\left(t^{\prime}, \mathbf{j o h n} \mathbf{n}^{\prime}, x\right)\right)\right)\right)$

Thus our analysis (a) predicts a common semantics across verbal and genitive possession constructions, which follows from the relational nature of possessed DPs, and (b) predicts the scope facts for free, without recourse to a silent syntactic formative (which we showed above is not warranted by any syntactic evidence). In the next section we briefly sketch some consequences of our analysis, including additional arguments for our analysis over syntactic and lexical decompositional analyses. $^{11}$

\section{Consequences and Extensions}

\subsection{Quantifier Scope for Possessed DPs}

Although our analysis is an extension of Partee's, there is one crucial difference: there is no need for the trivial exists ${ }^{\prime}$ predicate to saturate the scope of the possessed DP. In MRS quantifier scope is resolved post-compositionally, and a quantifier's scope may be any label that leads to a well-formed formula. For John has a sister, the poss ${ }^{\prime} \mathrm{EP}$ is the only possible scope for $a$, since have is pleonastic, predicting a meaning representation as in $\exists x\left[\operatorname{sister}^{\prime}(x) \wedge \operatorname{poss}^{\prime}\left(\mathbf{j o h n}^{\prime}, x\right)\right]$ (cp. Partee's predicted $\exists x\left[\right.$ sister $^{\prime}\left(\mathbf{j o h n}^{\prime}, x\right) \wedge$ exists $\left.\left.^{\prime}(x)\right]\right)$. Thus there is no need to saturate the scope argument of a sister within the VP, and thus no need for exists ${ }^{\prime}$.

This is a welcome result, since it produces the right semantics for non(in)alienable possession, where the definiteness effect does not apply and more types of quantifiers are allowed, including every. On Partee's analysis, if we assume a relational version of car à la Barker and a special raising denotation of every à la Partee's analysis of $a$, we would produce the representation in (41) for John has every car, which is clearly not correct (in fact, it is trivially true).

$$
\forall x\left[\left[\operatorname{car}^{\prime}(x) \wedge \operatorname{poss}^{\prime}\left(\mathbf{j o h n}^{\prime}, x\right)\right] \rightarrow \operatorname{exist}^{\prime}(x)\right]
$$

On our analysis, the representation is (42), where the scope of every can and must be poss $^{\prime}$ (there being nothing else for it to scope over), giving us the right semantics:

$$
\operatorname{every}^{\prime}\left(x, \operatorname{car}^{\prime}(x), \operatorname{poss}^{\prime}\left(\mathbf{j o h n}^{\prime}, x\right)\right)\left(\approx \forall x\left[\operatorname{car}^{\prime}(x) \rightarrow \operatorname{poss}^{\prime}\left(\mathbf{j o h n}^{\prime}, x\right)\right]\right)
$$

Of course, due to the definiteness effect, the only reading is focus or control.

\footnotetext{
${ }^{11}$ We have not provided an analysis here of the definiteness effect, though we assume this follows from how (in)alienable possession interacts with discourse context; see e.g. Tham (2006: 141).
} 


\subsection{Idiom Facts}

Since our analysis does not posit a HAVE formative, there can be no idioms of the form [ HAVE DP ], and thus we predict no systematic idioms across verbs of possession. The degree to which there are shared idioms, these are either due entirely to the possessed DP (as argued above for the flak/creeps), or due to common metaphors based on possession that follow from the shared underlying poss ${ }^{\prime}$ relation (and thus are not idioms). We furthermore predict that true idioms based on any of these verbs will not transfer, predicting that if have a baby means give birth to a baby, this meaning does not necessarily transfer to want, get, or give.

\subsection{Coordination}

Another advantage of our analysis is that it predicts the possibility of non-zeugmatic coordination of possessed DPs with alienable and inalienable possession:

John has a condo and a generous sister who pays all the bills.

On a standard analysis of have as a light verb with relational nouns and a heavy verb with non-relational nouns these facts would be mysterious. For us, it is the same light have, differing only in the semantics of the underlying possessor relation encoded by each DP.

\subsection{Multiple Possessors}

Furthermore, nothing prevents the Possessor Addition Rule from applying iteratively, or to lexically relational nouns. This predicts that it should be possible to get multiple possessors with the same range of semantics for any given DP realized as some combination of genitive possessors and raised possessors, something not necessarily predicted on an analysis where possession follows from the verb alone (either through a syntactic formative or lexical decomposition). The only constraint we predict is the semantic plausibility of multiple possessors, which follows from possible combinations of the different sorts of readings discussed above. For example, (44a) is acceptable on a reading that John is the brother, but Mary is either in charge of the sister on a focus have reading (for example to show her around town) or has control over her in some way. Likewise, $(44 b)$ is acceptable on a reading that John owns the car, but Mary has control of it or is in charge of it on a focus reading (e.g. to clean it).
a. Mary has John's sister.
b. Mary has John's car.

The sentences in (44) disallow readings where Mary is the sibling (in (a)) or owner of the car (in (b)) while John's bears a focus or control reading. Instead, the reverse is possible (e.g. Mary has control over John's sister/car), or else both Mary and John have focus or control roles. This is explained by the definiteness effect. 
(In)alienable possessums may not be definite when they are the complement of have. Since DPs with genitive possessors are interpreted as definite in English, if Mary is interpreted as an (in)alienable possessor this violates the definiteness condition.

Similar facts obtain for get, want, and give, although these verbs are not subject to the definiteness effect and thus it is possible to get all combinations of readings for multiple possessors realized with want, get, and give, as illustrated in (45) for want:

a. Kim wants Jan's car (for herself). $(\mathrm{Kim}=$ possessor, Jan $=$ focus $/$ control $)$

b. Kim wants Jan's car (for later). (Kim = control, Jan = possessor/focus)

c. Kim wants Jan's car (to clean). (Kim $=$ focus, Jan = possessor $/$ control $)$

Also, since the time variables for the EPs contributed by these verbs are distinct from that of poss' ${ }^{\prime}$ it is possible to have multiple possessors of the same type without contradiction (e.g. John got Sandy's car can mean John now owns the car Sandy owned at some previous time).

\section{Conclusion}

Let us review the main argument for our analysis, and then consider some of the theoretical implications. The same cluster of closely related semantic functions involving possession is observed in various verbs of possession (have, get, give, transitive want, and so on) and in the genitive construction. Originally identified for the verb have by Tham $(2005,2006)$, these functions are so-called 'inalienable possession' (predication of the property denoted by a relational noun), 'alienable possession' (true notional possession), 'control possession' (physical control or abstract entitlement by a cognitive agent), and 'focus possession' (new information relative to a presupposed open proposition). The question is how to capture the clustering of these functions across diverse contexts.

One way to capture the clustering of these functions is to posit an ambiguous non-logical semantic constant (our poss') with just those functions. Indeed, a semantic constant denoting possession has been posited before in two alternative approaches to verbs of possession: those employing such a constant as an element of the lexical decomposition, and those employing such a constant as a silent syntactic formative. For both approaches, the main form of evidence that has been cited in the previous literature involves sublexical scope by adverbials such as durative ('for an hour') and restitutive ('again') adverbials. Broadly speaking, then, the polysemic clustering observed here provides further evidence for any analysis involving such a constant.

However, we have pointed out weaknesses in both of these approaches and suggested a third way. The problem with the syntactic approach is that the putative silent syntactic formatives would have to be systematically prevented from forming true non-compositional idioms. The minimal granularity of idiom-forming elements 
is actual words, not putative syntactic formatives such as HAVE. Moreover, there is no syntactic evidence for such formatives: the syntax behaves exactly as if they did not exist. On the other hand, the lexical decomposition approach works for the verbs but does not extend to possessive noun phrases like John's book where the possessive relation appears to be constructionally rather than lexically induced.

We take the possessive noun phrases as our starting point, and extend this account to the verbs. For the possessive noun phrases we posit a general process allowing for the addition of a possessor argument to a non-relational noun such as book, while assuming an inherent possessor argument for relational nouns such as sister (essentially following Barker 1995). Thus endowed with a possessor argument role, the noun can be combined either with the genitive possessor or with any of the possessive verbs. When such a noun combines with a possessive verb, the verb adds extra meaning, with the exception of have, which has nothing to add since possession is already encoded on the noun. Hence have is treated as a light verb, as proposed already by Partee (1999) for have when it takes relational nouns like sister (as in John has a sister), but extended here to apply to all instances of have, even those involving true possession (as in John has a book).

The present account has much in common with lexical decomposition analyses in which the decomposition of a verb of possession contains the constant HAVE (recall (4a)). Both are lexicalist accounts, for example. But they have somewhat different implications. HAVE has always been a bit of an unwelcome guest among the inventory of decomposition constants that includes CAUSE and BECOME. While CAUSE and BECOME are morphologized in many languages as causative and inchoative morphemes, respectively, one does not often find languages where verbs of possession bear a special possessive morpheme. Even in languages lacking regular causative or inchoative morphology such as English, CAUSE and BECOME are motivated by verb and adjective diathetic paradigms like the transitive/inchoative/ stative triples such as cool in John cooled the soup vs. The soup cooled vs. The soup is cool. But the putative HAVE in lexical decompositions is paradigmatically inert: it cannot be stripped away from a verb to yield a different verb or adjective. In short, lexicon-internal evidence for HAVE seems to be sorely lacking. The main evidence comes from syntax (the adverbial scope facts) and the polysemy clustering facts noted here. While the evidence is not conclusive, this suggests to us an origin for the possessive semantics that lies outside the lexicon of verbs. We hypothesize that the possession relation arises through a productive rule applying to nouns, reflecting the simple intuition that things in general can serve as possessions.

\section{References}

Barker, Chris: 1995, Possessive Descriptions. CSLI Publications, Stanford.

Barwise, Jon and Robin Cooper: 1981, 'Generalized Quantifiers and Natural Language', Linguistics and Philosophy.

Copestake, Ann, Dan Flickinger, Carl Pollard, and Ivan A. Sag: 2005, 'Minimal 
Recursion Semantics: An Introduction', Research on Language and Computation 3, 281-332.

Dowty, David: 1979, Word Meaning and Montague Grammar. Reidel, Dordrecht.

Egg, Marcus: 1999, 'Deriving and Resolving Ambiguities in wieder-Sentences', in Proceedings of the 12th Amsterdam Colloquium.

Ginzburg, Jonathan and Ivan A. Sag: 2000, Interrogative Investigations: The Form, Meaning, and Use of English Interrogatives. CSLI Publications, Stanford.

Harley, Heidi: 2003, 'Possession and the Double Object Construction', in P. Pica and J. Rooryck (eds.), Linguistic Variation Yearbook 2, 31-70. John Benjamins, Amsterdam.

Harley, Heidi: 2004, 'Wanting, Having, and Getting: A Note on Fodor and Lepore 1998', Linguistic Inquiry 35, 255-267.

McCawley, James D.: 1974, 'On Identifying the Remains of Deceased Clauses', Language Research 9, 73-85.

Partee, Barbara H.: 1999, 'Weak NP's in HAVE Sentences', in J. Gerbrandy, M. Marx, M. de Rijke, and Y. Venema (eds.), JFAK, a Liber Amicorum for Johan van Benthen on the occasion of his 50th Birthday, 39-57. University of Amsterdam, Amsterdam.

Pollard, Carl and Ivan A. Sag: 1994, Head-Driven Phrase Structure Grammar. The University of Chicago, Chicago, IL.

Pratt, Ian and Nissim Francez: 2001, 'Temporal Prepositions and Temporal Generalized Quantifiers', Linguistics and Philosophy 24, 182-222.

Pustejovsky, James: 1995, The Generative Lexicon. MIT Press, Cambridge.

Rappaport Hovav, Malka and Beth Levin: 2008, 'The English Dative Alternation: A Case for Verb Sensitivity', Journal of Linguistics 44, 129-167.

Richards, Norvin: 2001, 'An Idiomatic Argument for Lexical Decomposition', Linguistic Inquiry 183-192.

Ross, John Robert: 1976, 'To Have Have and to Not Have Have', in M. A. Jazayery, E. C. Polomé, and W. Winter (eds.), Linguistic and Literary Studies in Honor of Archibald A. Hill, 263-270. Mouton, The Hague.

Tham, Shiao Wei: 2006, 'The Definiteness Effect in English Have Sentences', in P. Denis, E. McCready, A. Palmer, and B. Reese (eds.), TLS 8, 137-149. Cascadilla Proceedings Project, Somerville.

Vikner, Carl and Per Anker Jensen: 2002, 'A Semantic Analysis of the English Genitive. Interaction of Lexical and Formal Semantics', Studia Linguistica 56, 191-226.

Wechsler, Stephen: 2008, 'Idioms, Light Verbs, and Lexical Decomposition'. NORMS Workshop on Argument Structure, Lund University, February 6. 